\title{
إمكانيات الطينات المحلية في المملكة العربية السعودية لإثراء جماليات الخزف المعاصر المر البرات
}

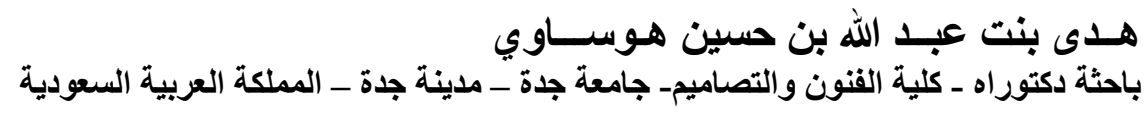
د. منال بنت صالح بن عثمان الصالح

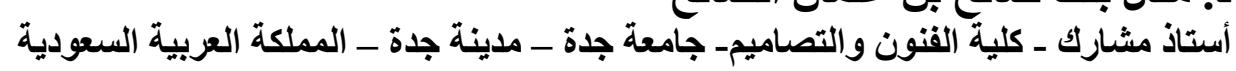

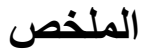

تتاولت الدارسة الطينات المحلية بالمملكة العربية السعودية وكيف استفاد منها الخز افون والحرفيّون في إيجاد الكثير من الأواني الخزفية التي ميزت كل منطقة عن الأخرى، حيث إن الطينات المحلية أوجدت أفق الإبداع

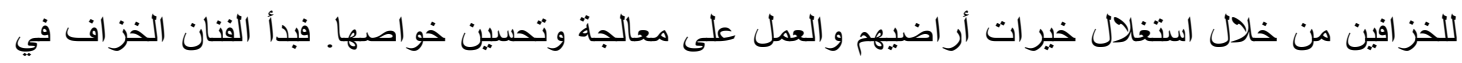

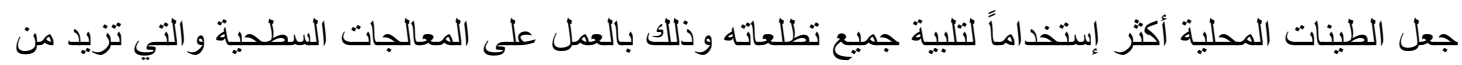
جمالية القطع الخزفية المعدة من هذه الطينات من خلال الاستفادة مما تميزت به هذه الطينات من قوة وصلابة وتحمل درجات الحرارة المختلفة. فتحددت مشكلة الدراسة في التساؤل التالي هل يمكن الاستفادة من إمكانيات الطينات المحلية في المملكة العربية السعودية لإثراء جماليات الخزف المعاصر؟ كما هدفت الدراسة إلى التعرف على إمكانيات الطينات المحلية وطرق تتكيلها. ومدى امكانية انتاج أو اني خزفية مبتكرة بالطينات المحلية واثراء

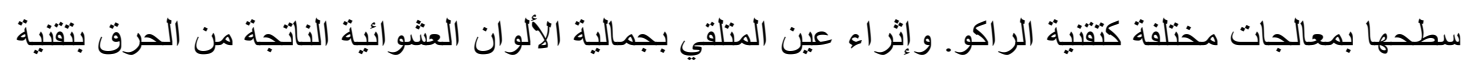
الر اكو. و افترضت الدراسة أنه يمكن إعداد طينات محلية، ومعالجتها لتكون صالحة للتشكيل الخزفي، وتتحمل ولتهل مختلف درجات الحرارة. وتقنية الحرق بالر اكو تسهم في انتاج أواني خزفية من الطينات المحلية بشكل معاصر ذات حلول جمالية مختلفة. وتلخصت اهم النتائج على ايجاد طينات محلية صالحه للتشكيل وتحمل الصدمات الحرارية. . وان الاواني الخزفية التقليدية والمنتجة من الطينات المحلية مصدر لإلهام الخزافين المعاصرين. فالتعبيرية التجريدية فتحت افاق جمالية لابتكار تداخلات لونية عشو ائية بو اسطة الحرق تقنية الر اكو. 


\title{
The Potential of Local Clays in The Kingdom of Saudi Arabia to Enrich The Aesthetics of Contemporary Ceramics
}

\author{
Huda bint Abdullah bin Hussein Hawsawi \\ PhD researcher - College of Art and Design - University of Jeddah - Jeddah - Kingdom \\ of Saudi Arabia \\ Dr. Manal bint Saleh bin Othman Al Saleh \\ Associate Professor - College of Art and Design - University of Jeddah - Jeddah - King- \\ dom of Saudi Arabia
}

\begin{abstract}
The study takes about Saudi Arabia's local clays and how potters get benefit from it to make several ceramics which give feature to each area from other, whereas the local clay created potters' creativity through exploitation their lands and working on processing and improving its properties. Ceramic artist makes the local clay more using to cover all vision through working on surface treatments that increase the beauty of ceramics which made from this clay and getting benefit from what the clay has like strength and withstands different temperatures. Wherefore, the problem statement gets stuck on the question that say could get benefit from Saudi Arabia local clay's possibilities to enrich beauty of contemporary ceramics? The statement goal guide to recognize for local clay's possibilities and its forming methods. In addition, the extent of the possibility to produce innovative ceramics pieces through local clay and enriching its surface by different treatments like Raku firing. Enriching spectator's eye by beauty of random colors which came from Raku firing. The hypotheses statement that can prepare local clay and treatment it to be valid for ceramics formation and withstands different temperatures. The Raku firing contribute for produce of local clay's contemporary ceramic which has different solution of beauty. The important consequences summarize on finding the valid local clay for formation and withstands different temperatures. The tradition ceramics which made from local clays considered as inspiration for contemporary ceramics artists. Abstract Expressionism open aesthetic prospects to innovation of random colors overlaps by Raku firing technique.
\end{abstract}

Keywords: clay pottery, contemporary ceramics, potters, craftsmen. 


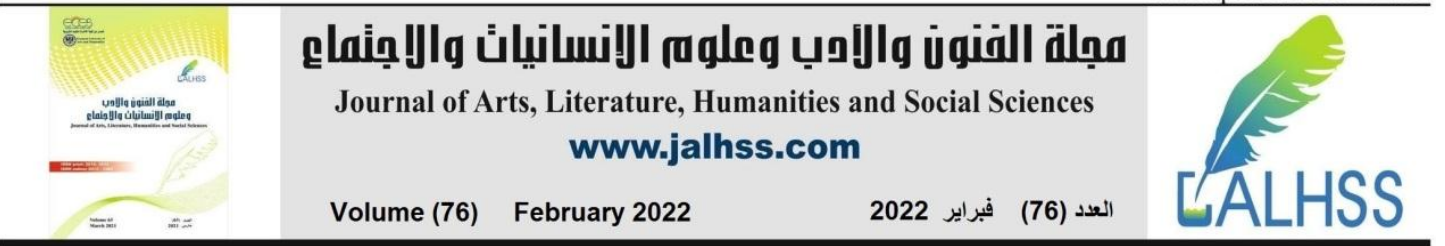

أوجد الله تعالي الطين في كل بقاع الأرض، فهو اللبنة التي خلق منها الانسان؛ فقد ذكر الله تعالى في محكم تنزيله

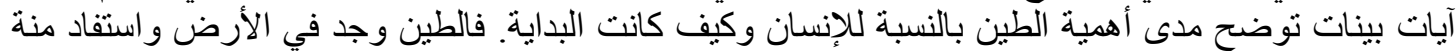

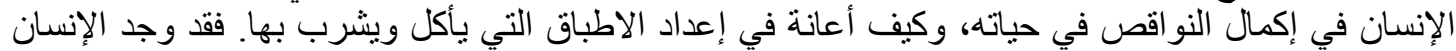

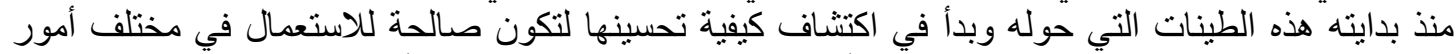

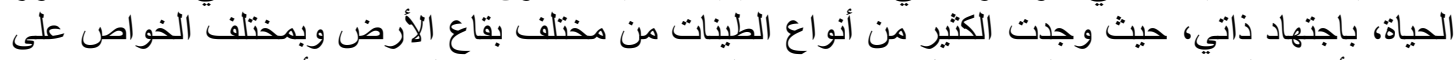

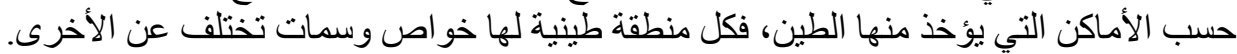

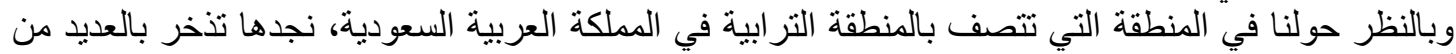

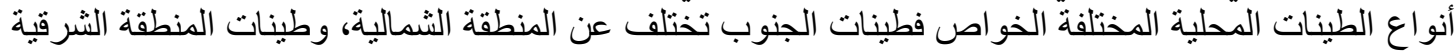

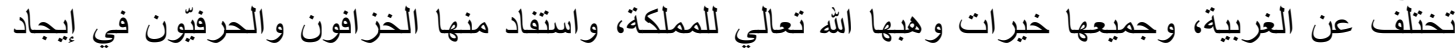

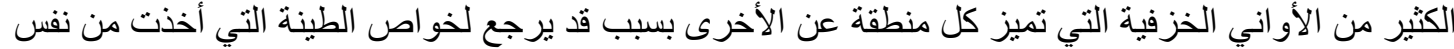

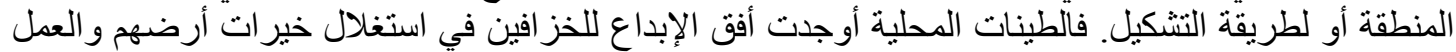

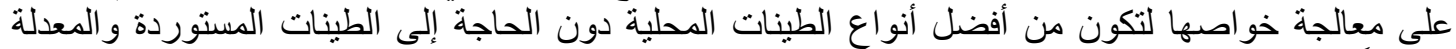

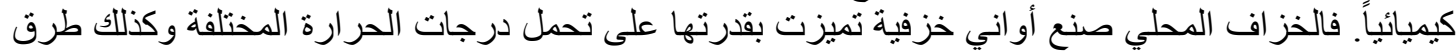

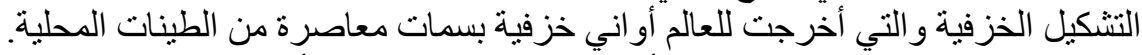

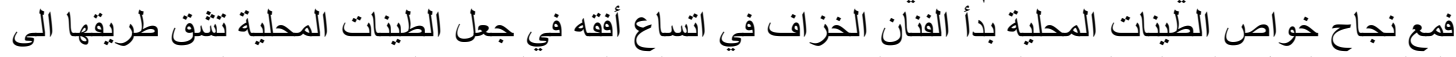

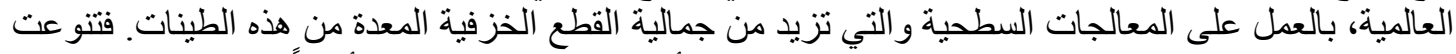

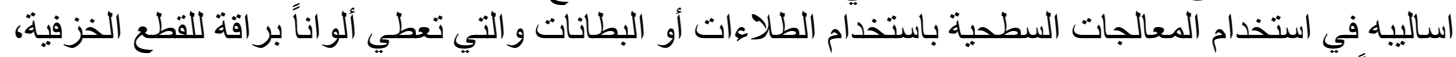

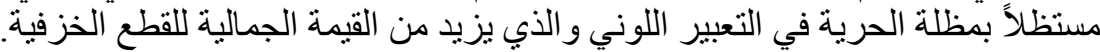

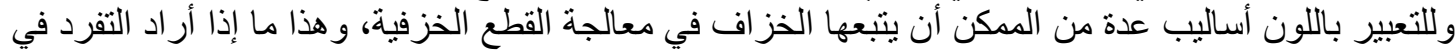

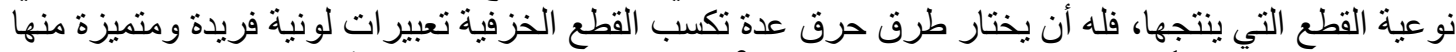

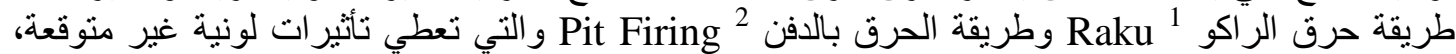

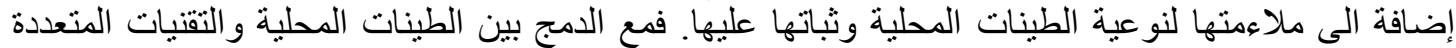

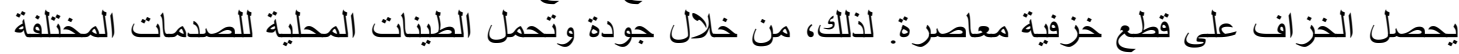
يمكن الاستفادة منها في إنتاج أواني خزفية بواسطة عجلة الخزاف ومن ثم إثراءها بالمعالجات السطحية

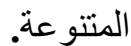

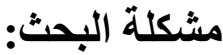

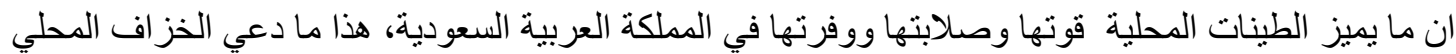

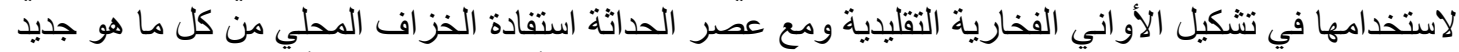

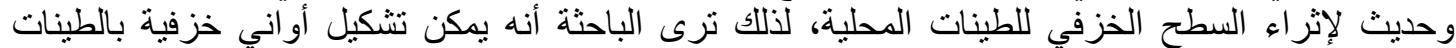

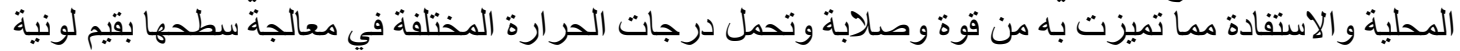

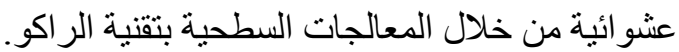

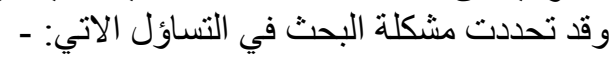
هل يمكن الاستفادة من إمكانيات الطينات التحلية في المملكة العربية السعودية لإثر اء جماليات الخزف المعاصر؟

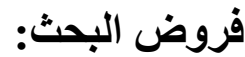
1- يمكن الاستفادة من الطينات المحلية لإنتاج أو اني خزفية بواسطة عجلة الخز اف و إثراء معالجات السطح

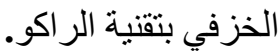

2- إمكانية اعداد طينات محلية، ومعالجتها لتكون صالحة للتشكيل الخزفي، وتتحمل مختلف درجات التهات الحر ارة. 3- تسهم تقنية الحرق بالر اكو في انتاج أواني خزفية من الطينات المحلية بشكل معاصر ذات ذلينة دلول جمالية

مختلفة.

(Wandless, هو عملية حرق بدرجات حرارة منخفضة وسريعة تنتج تأثير ات سطحية لونية مثيرة بالصدفة: Raku ${ }^{1}$ 2006) هو عملية حرق في ثقب محفور في الأرض، تحتوى الحفرة على الحرارة بحيث تصل الى درجات حرارة : Pit Firing ${ }^{2}$

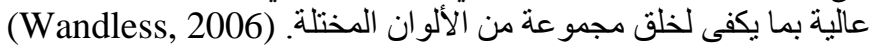




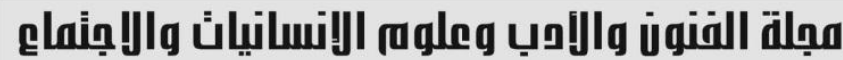

Journal of Arts, Literature, Humanities and Social Sciences www.jalhss.com

4- الاستلهام من الألوان التعبيرية التجريدية في معالجات السطح الخزفي من خلال الألوان الناتجة من الحرق

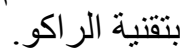

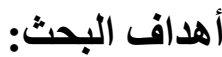

1- انتاج أو اني خزفية مبتكرة بالطينات المحلية من خلال عجلة الخز اف و اثر اء معالجات السطح الخزفي بتقنية

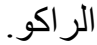
2- التعرف على إمكانيات الطينات المحلية وطرق تشكيلها بعجلة الخز اف.

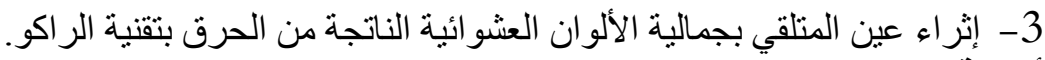
أهمية البحث: أبراء

1- إيجاد طينات محلية صالحة لتتكيل أواني خزفية محلية ومعالجة السطح بالقيم اللونية للتجريدية التعبيرية الناتجة من الحرق بتقنية الر اكو. 2- افتقار الخز افين التقليدين في المملكة العربية السعودية الى إيجاد حلول جمالية لسطح الأو اني الخزفية بتقنية

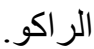

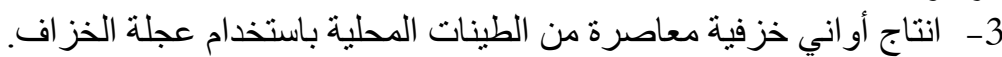
4- - دراسة القيم اللونية للتجريدية التعبيرية في الاو اني الخزفية من خلال الحرق بتقنية الر اكو. حدود البحث: • الحدود المكانية: المملكة العربية السعودية (حائلــ الرياض- و ادي السيل بمنطقة مكة المكرمة)

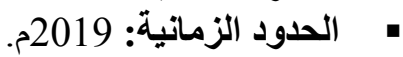

الطينات المحلية في المملكة العربية السعودية. منهج البحث وإجراء|تهة: الوصفي (التحليلي): فكر المدرسة التجريدية التعبيرية في عشواتية التئية الألوان.

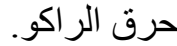

التجريبي: انتاج أو اني خزفية ذات معالجات سطحية بتقنية الر اكو، بواسطة عجلة الخز اف.

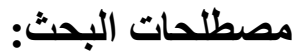

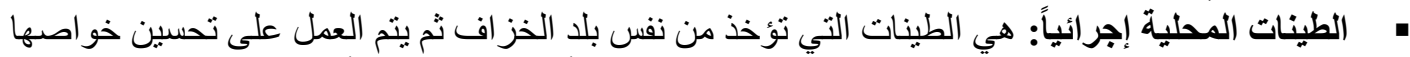

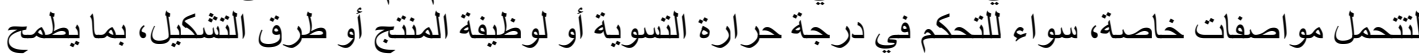

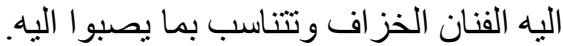

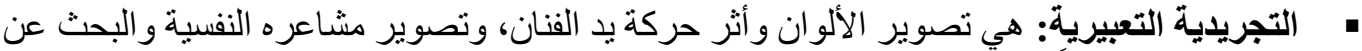

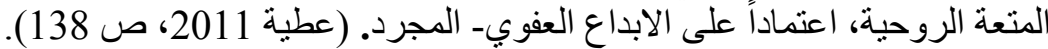

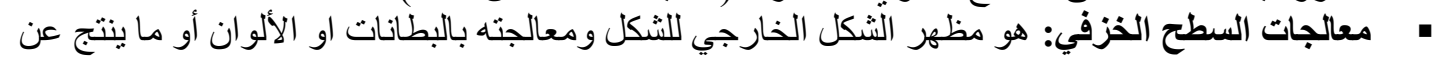
البناء بوحدات لونية. (فيرق، 1991).

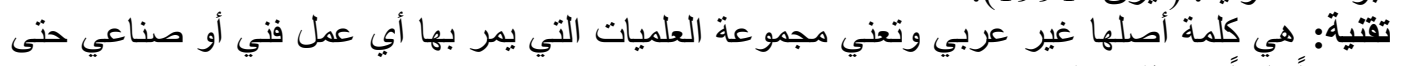

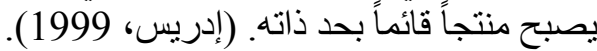

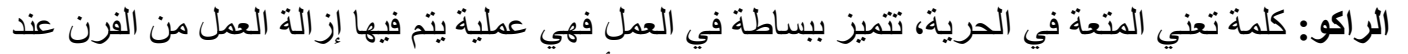

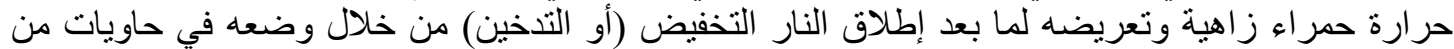

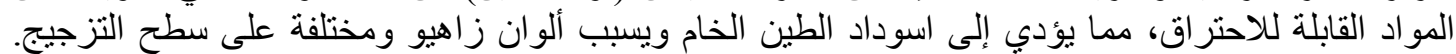

(Branfman, 2020)

المحور الأول: الطينات المحلية في المملكة العربية السعودية 


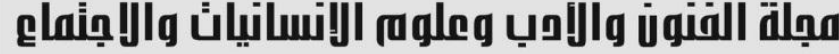

Journal of Arts, Literature, Humanities and Social Sciences www.jalhss.com

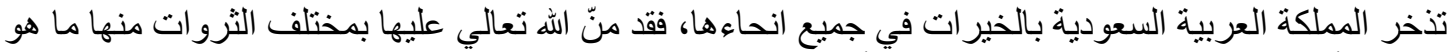

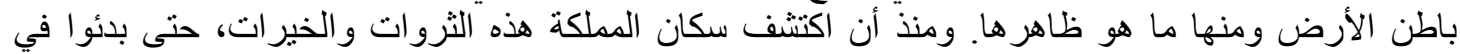

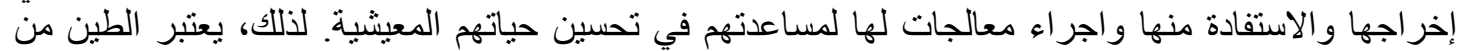
الخيرات التي وجدات في المملكة واستفاد منها سكانها في إعداد الأواني الخزفية و الفخارية التي يستخدمونها في لئي

حياتهم اليومية.

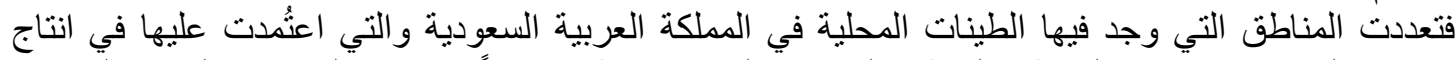

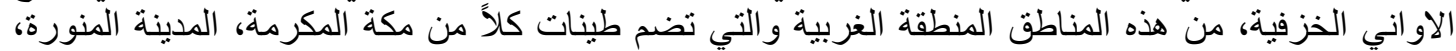

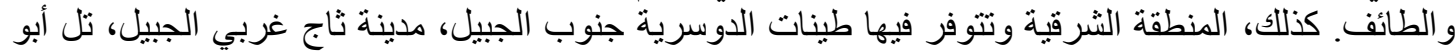

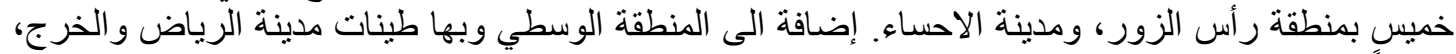

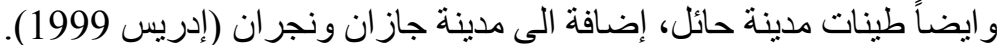

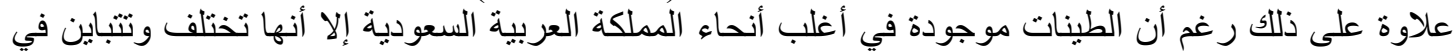

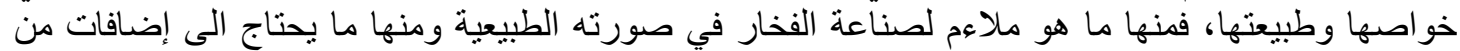

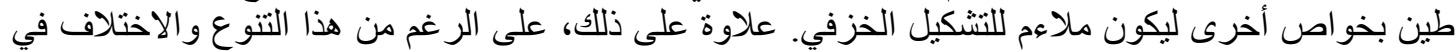

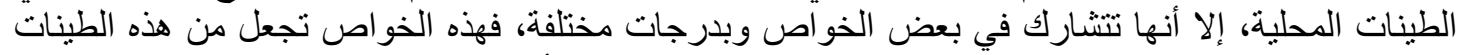

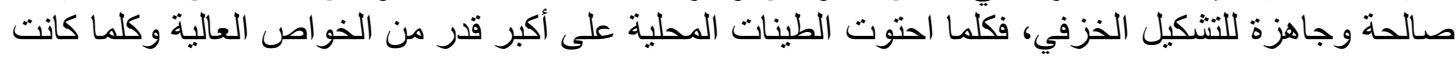

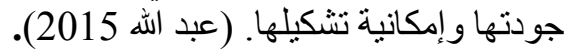

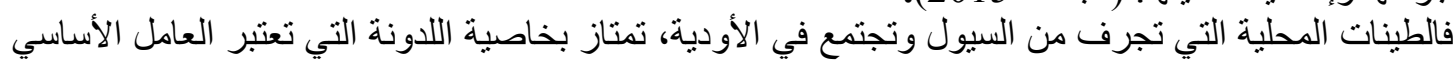

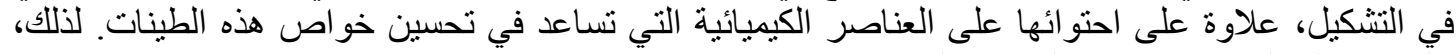
فالطبنات المحلية تتقسم حسب الميل المناطق الى الى قسمين:

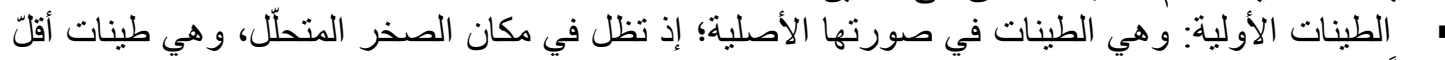

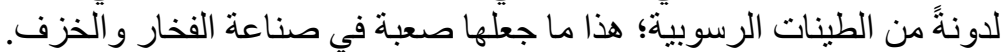

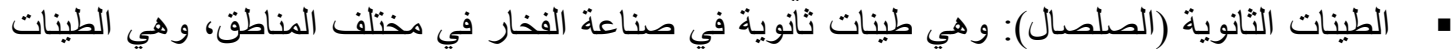

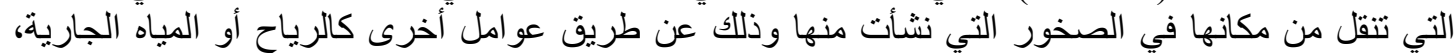

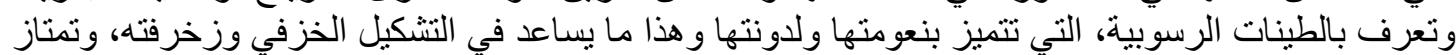

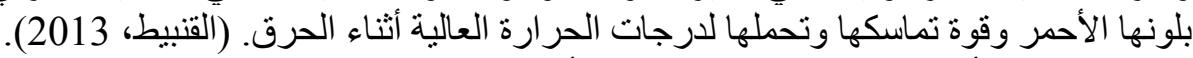

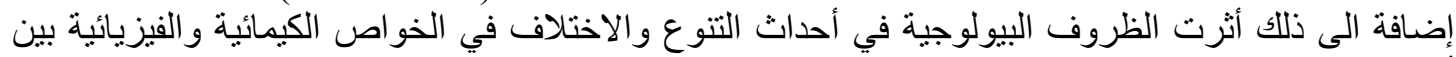

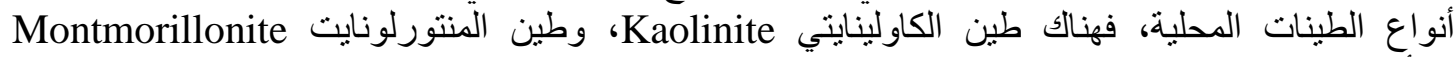

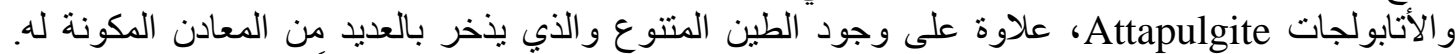

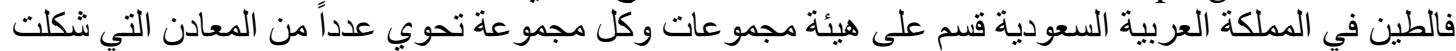

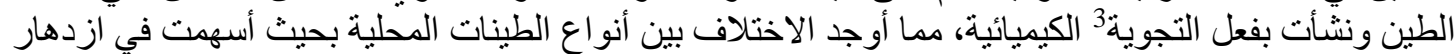

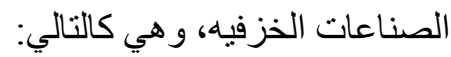

مجمو عة معادن الكاولينايت (Kaolinite) و وتشمل معادن الكاولينايت و الديكيت و النكريت و غير ها.

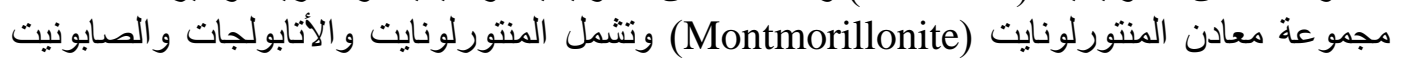

مجمو عة معادن الميكا المتيئة: وتشمل معدن الإليت و غيرة من المعادن. (مجمو عة من المؤلفين، 2000)

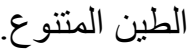

الطينات المحلية تمر بمر احل اعداد لتكون جاهزة للاستخدام، فالخز افين يقومون بإعداد الطينات المحلية بالطرق الطينة

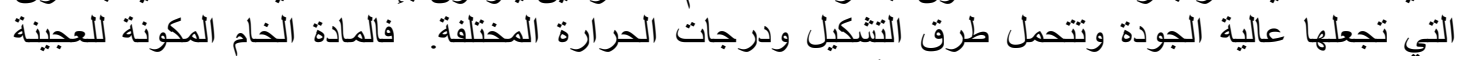
الطينية المحلية والتي تستخدم في صناعة الأواني الفخارية تتكون من ثلاثة عناصر منساوية النسب، هي الماء النياء

3 التجوية: هي عملية تفتت وتحلل الصخور و التربة و المعادن على سطح الأرض أو قربه بو اسطة العو امل الجوية السائدة دون نقل الفتات من مكانه. 


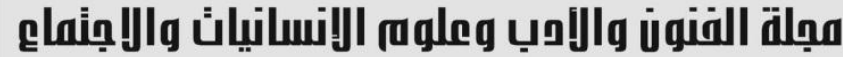

Journal of Arts, Literature, Humanities and Social Sciences www.jalhss.com

Volume (76) February 2022

العدد (76) فبراير 2022

و الثو ائب والتربة، لذلك تميزت بتجانسها وقابليتها للتشكيل و الزخرفة، إضافةً إلى خلو ها من المسمات و الكتل

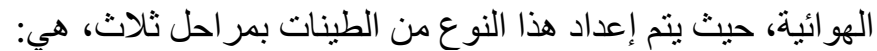
• المرحلة الأولى: وهي أهم المراحل، حيث يعتمد الخزافين على هلى الطينة الناعمة النقية من دون إضافة مو اد

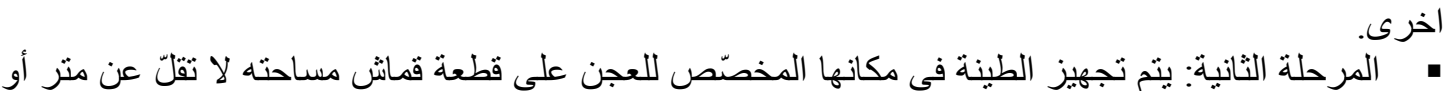

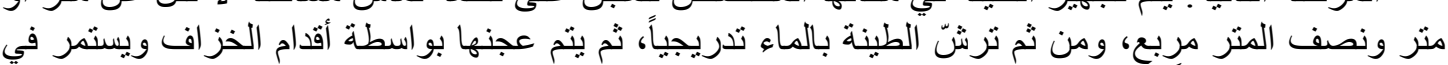

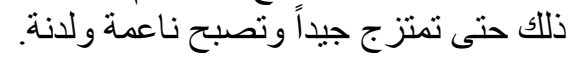

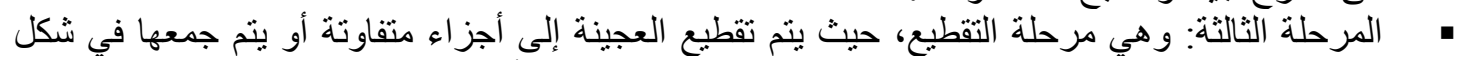

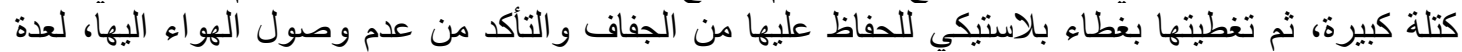

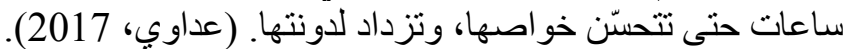

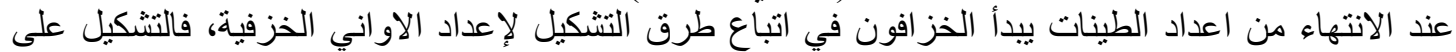

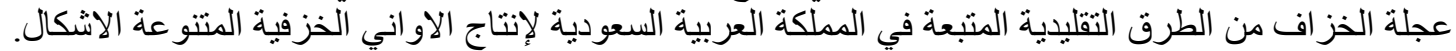

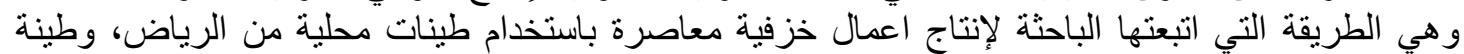
حائلّ، وطينة السيلّ من المنطقة الغربية.

\section{المحور الثاني: المدرسة التعبيرية التجريدية} المدرسة التعبيرية التجريدية Abstract Expressionism

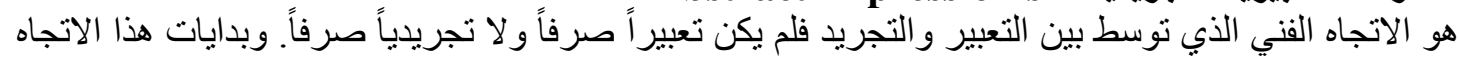

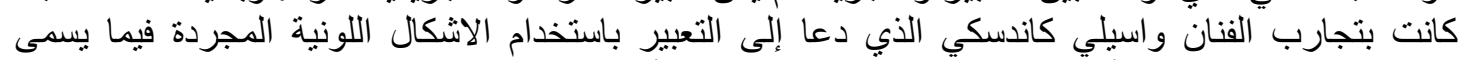

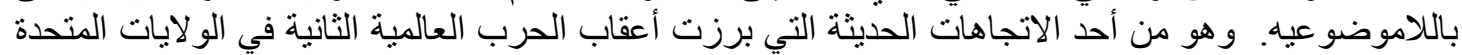

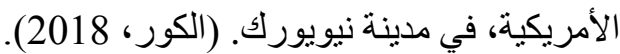

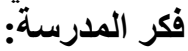

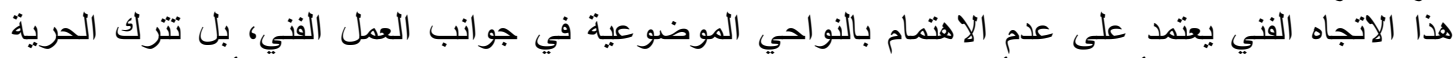

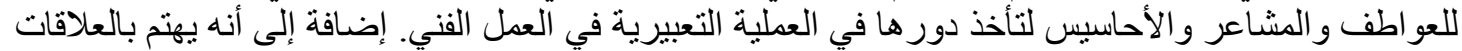

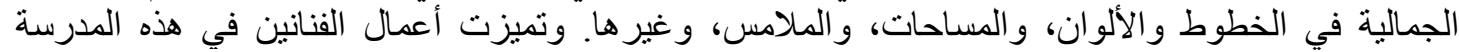

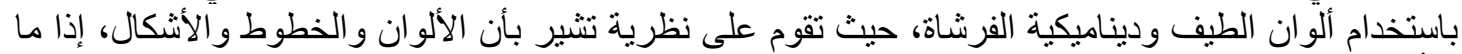

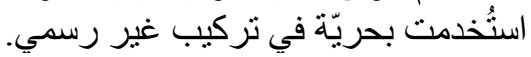

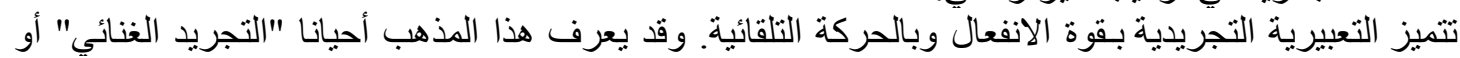

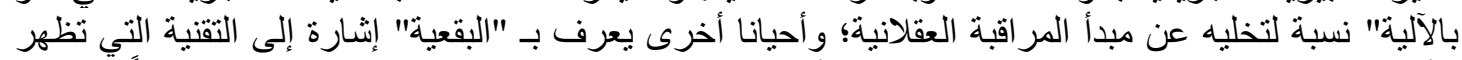

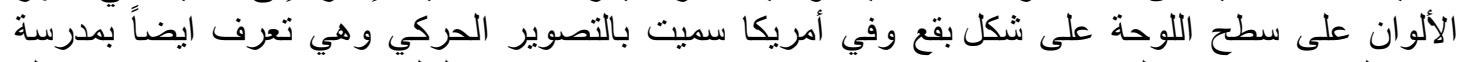

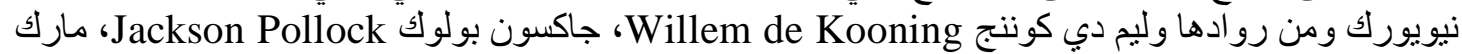

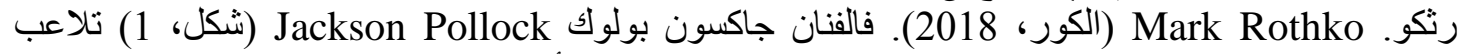

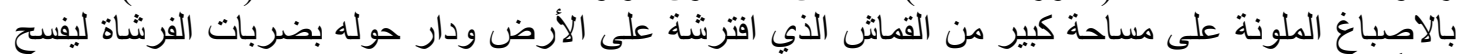

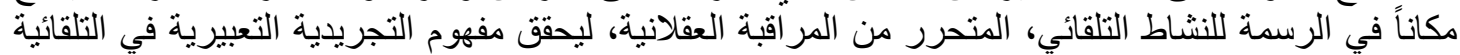

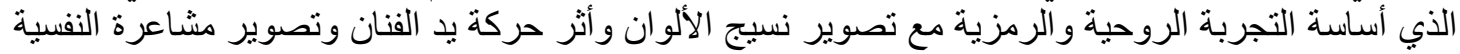

$$
\text { و البحثث عن المتعة الروحية. (عطية، الرية ولرية 2011). }
$$
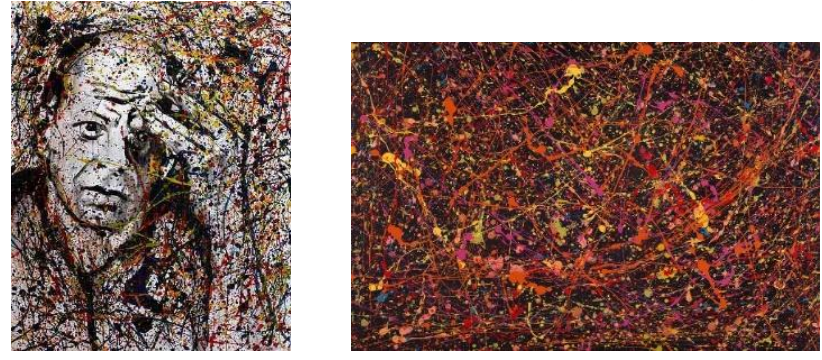


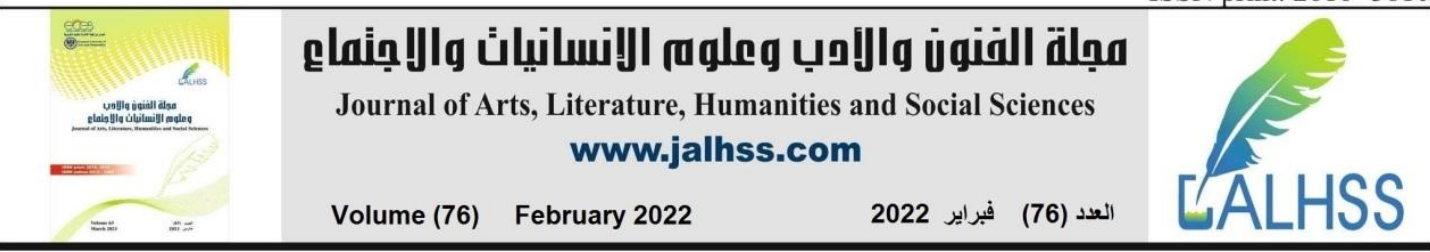

$$
\text { شكل (1) }
$$

اسم الفنان: Jackson Pollock

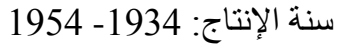

https://www.moma.org/calendar/exhibitions/1553 المرجع:

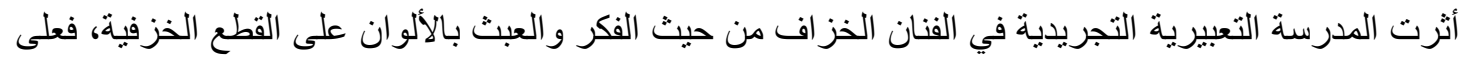

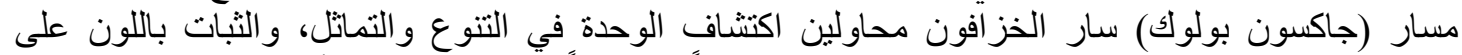

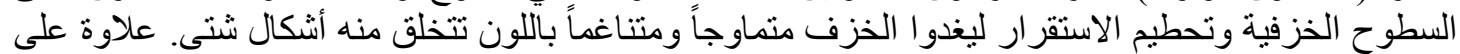

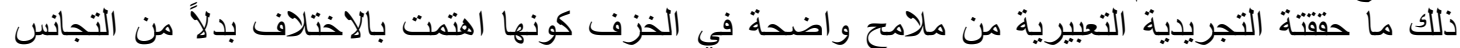
و التشتت. (كاظم، 2014).

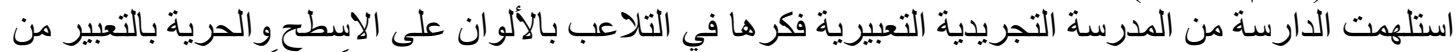

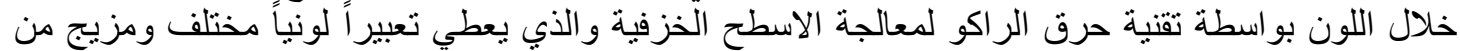
الألوان وحرية في النشاط التلقائي اللوني.

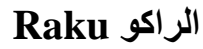

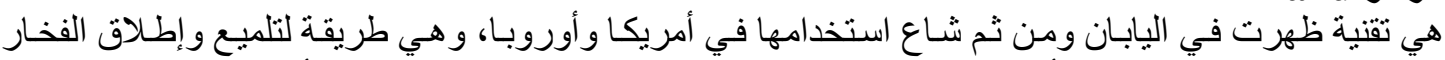

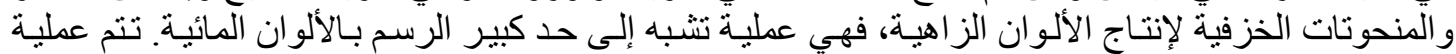

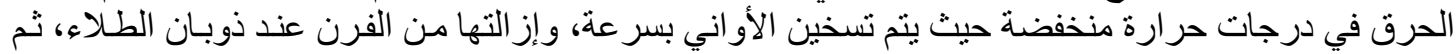

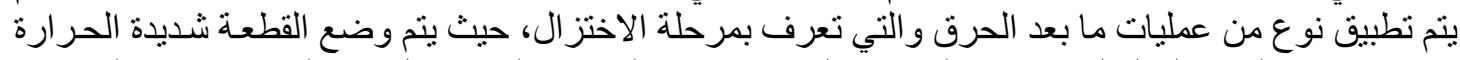

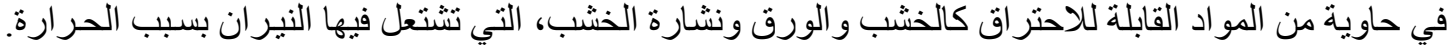

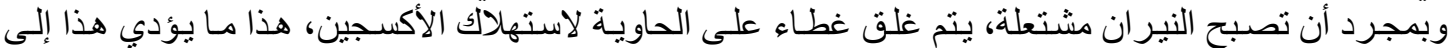

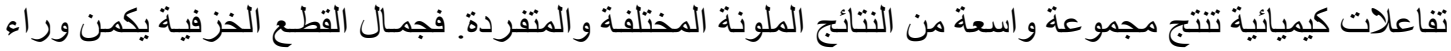

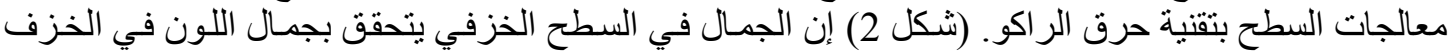

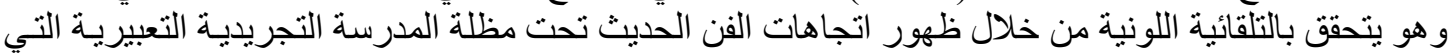

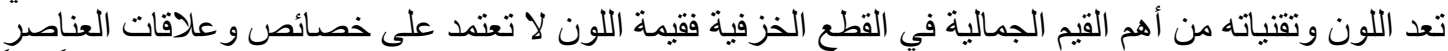

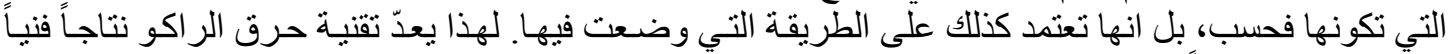
يبدع فيه الفنان نظر أ لأسلوبه وتقنيته المتفردة بالجمال و السعادة. (سليمان، 2016).
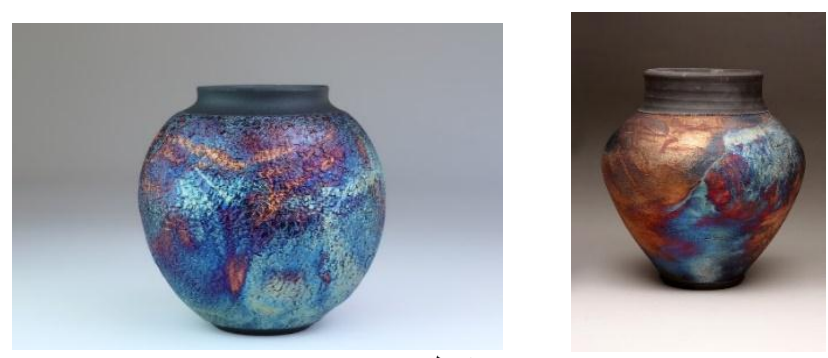

شكل (2) (1)

الفنان: Keri LaVonne Fischer سنة الإنتاج: 


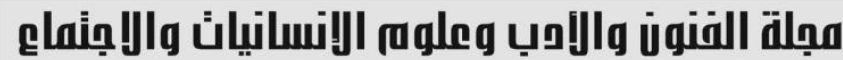

Journal of Arts, Literature, Humanities and Social Sciences www.jalhss.com

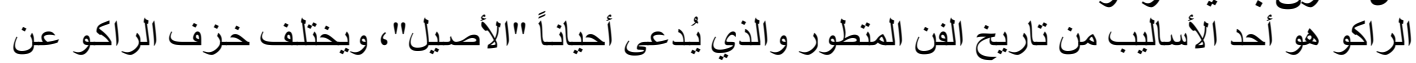

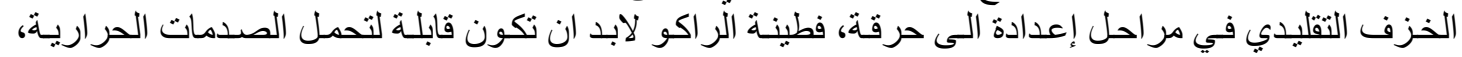

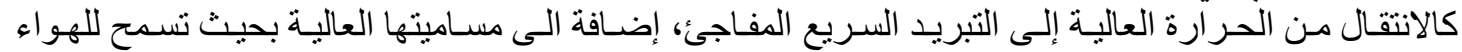
بالخروج بحرية تامة. (عنمان، 2019). و لابد عند الحرق بتقنية الر اكو مر اعاة النقاط التاليه:

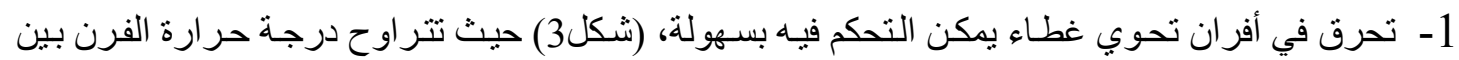

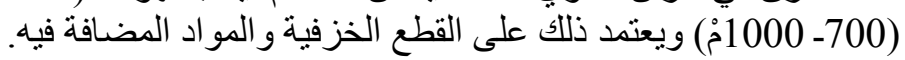
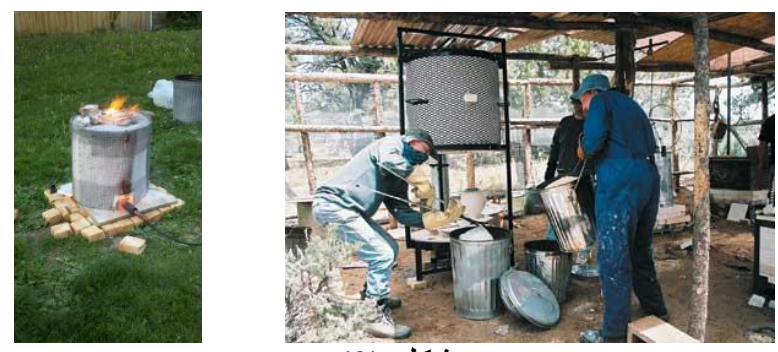

شكل (3)

$$
\text { افران الر اكو }
$$

https://ceramicartsnetwork.org/daily/firing- المرجع: techniques/raku-firing/helpful-tips-on-purchasing-araku-kiln/

2- في مرحلة وصول درجة الحرارة إلى 1000مُ تتحول القطع الخزفية بفعل ارتفاع درجـة الحر ارة إلى هيئة

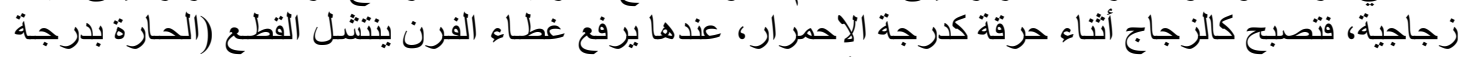
الاحمر ار ) و هي في حالة التو هج بو اسطة ملقط أو ماسك، (شكل 3- تُشقط القطعه المتوهجة في حاوية معدنية مملوءة بمادة قابلة للاشتعال مثل نشـارة الخشب أو الورق (شكل
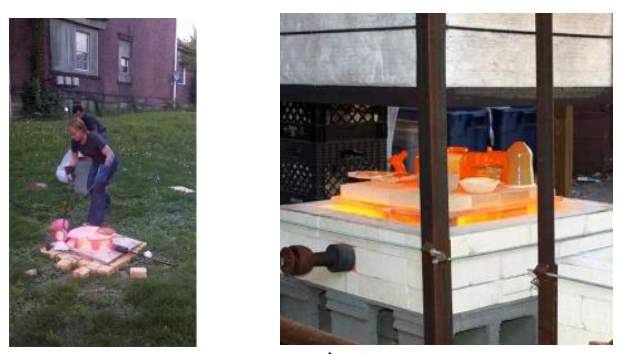

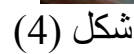

لحظة نو هج القطعه الخزفية

https://unionproject.org/blog/what-raku المرجع: 


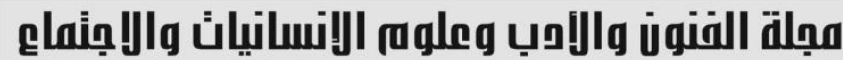

Journal of Arts, Literature, Humanities and Social Sciences www.jalhss.com
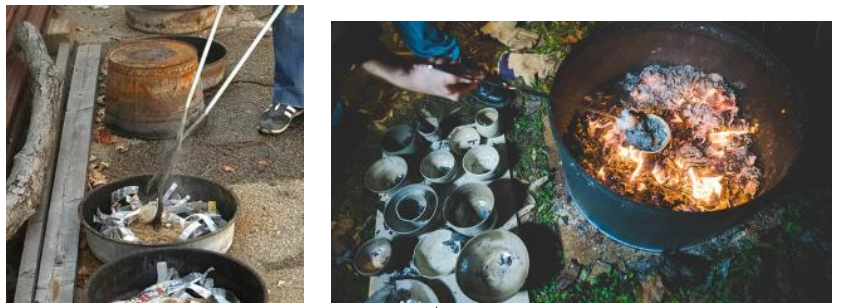

شكل (5)

لحظة اسقاط القطع المتوهجة في مادة قابلة للاشتعال

المرجع:

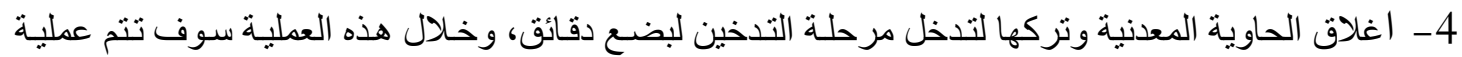

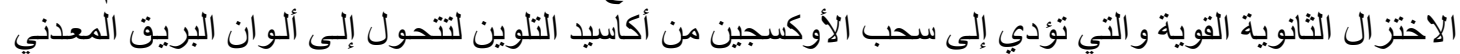

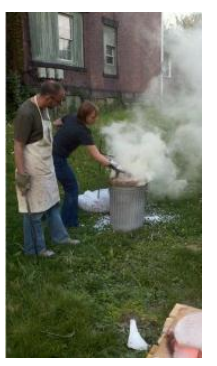

ويظهر اللون الأسود المعتم في الأجزاء غير المزججة. (شكل6)

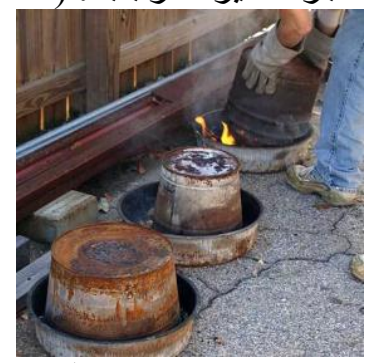

شكل (6)

لحظة عملية الاختزال

https://unionproject.org/blog/what-raku المرجع:

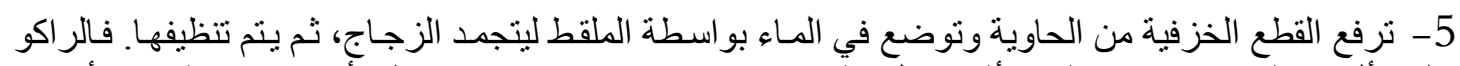

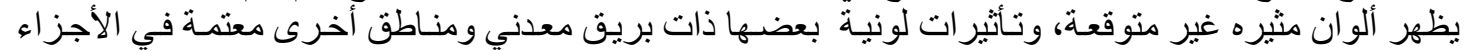
الخالية من الزجاج. (شكل 7) (العابدي،2014). 


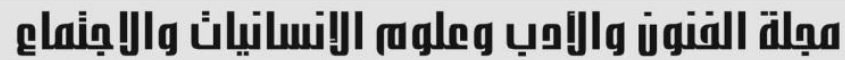

Journal of Arts, Literature, Humanities and Social Sciences www.jalhss.com

$=\quad$ Volume (76) February $2022 \quad 2022 \quad$ العدائ (76)

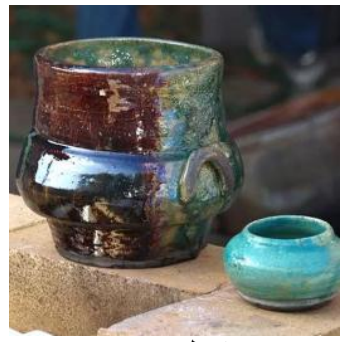

شكل (7)

$$
\text { الثكل النهائي للقطع المحروقة بالر اكو }
$$

https://ceramicartsnetwork.org/daily/firing-techniques/raku- المرجع firing/charlie-and-linda-riggs-naked-raku-technique/

المحور الثالث: التجربة العملية للباحثة:

شكلت الباحثة مجمو عة من الأو اني الخزفية لطية لطينات محلية بو اسطة عجلة الخز الفئة بتصميمات معاصرة من خلال التغيير و التناعب في الثنكل الخزفي التقليدي.

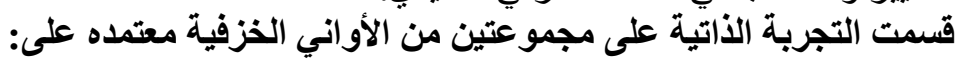

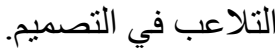

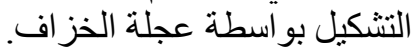

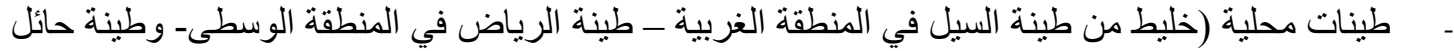

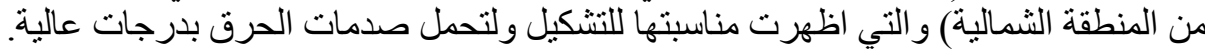

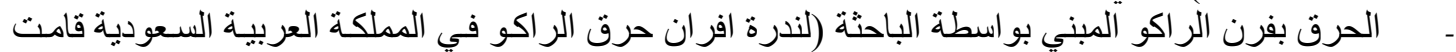

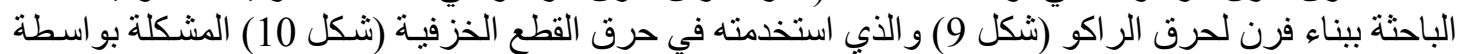

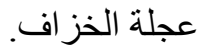

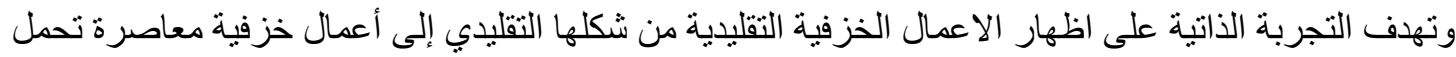

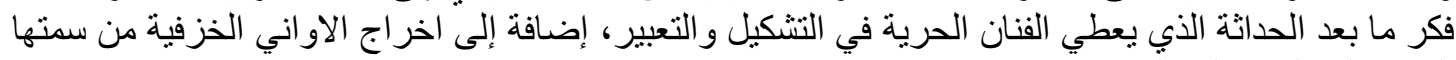
النفعية إلى السمة الجمالية.
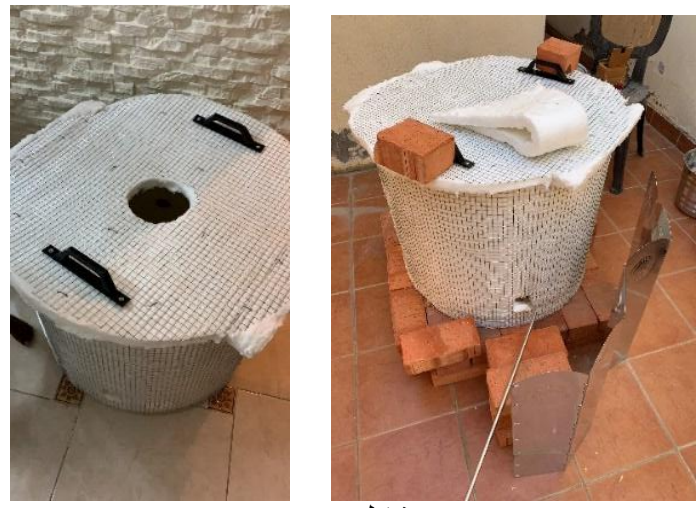

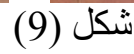




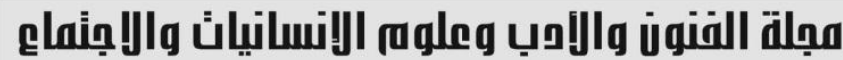

Journal of Arts, Literature, Humanities and Social Sciences www.jalhss.com

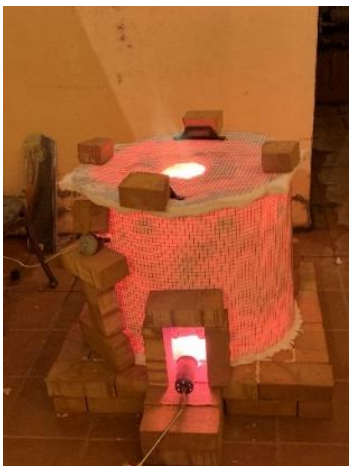

شكل (10)

$$
\text { فرن لحرق الر اكو }
$$

Concept of Ceramics Works مفهوم الأعمال الخزفية للتجربة العملية

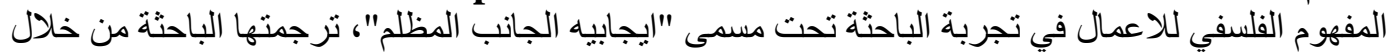

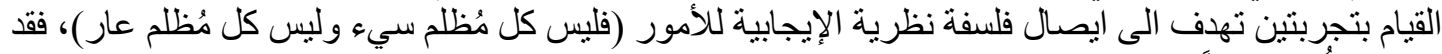

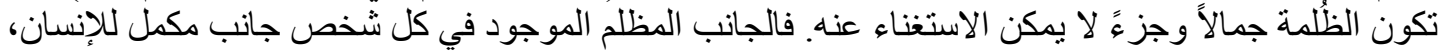

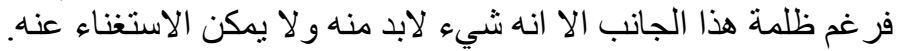

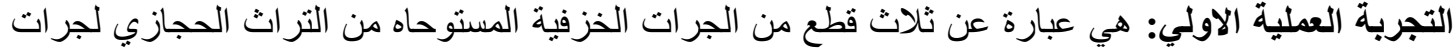

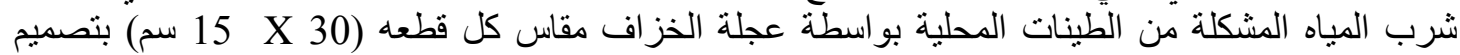

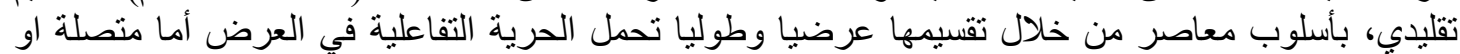
منفصلة عن بعضي، بأسلوبا. التجربة العملية الثانية: تشكيل مجمو عة متكررة من أطباق الطعام الخزفية الاسطوانية الثكل بمقاسات مختلفة

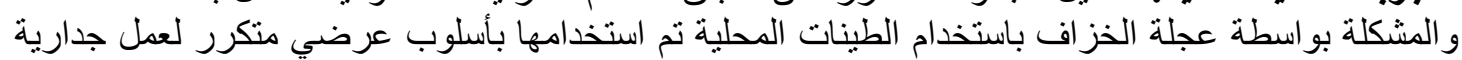
متنالية لا نهائية المساحة. مجموعة أعمال التجربة التية العملية الاولي:

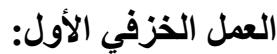




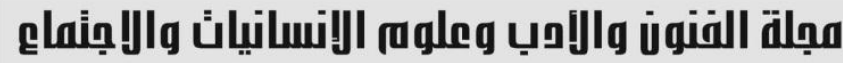

vallatianal alas

Journal of Arts, Literature, Humanities and Social Sciences www.jalhss.com

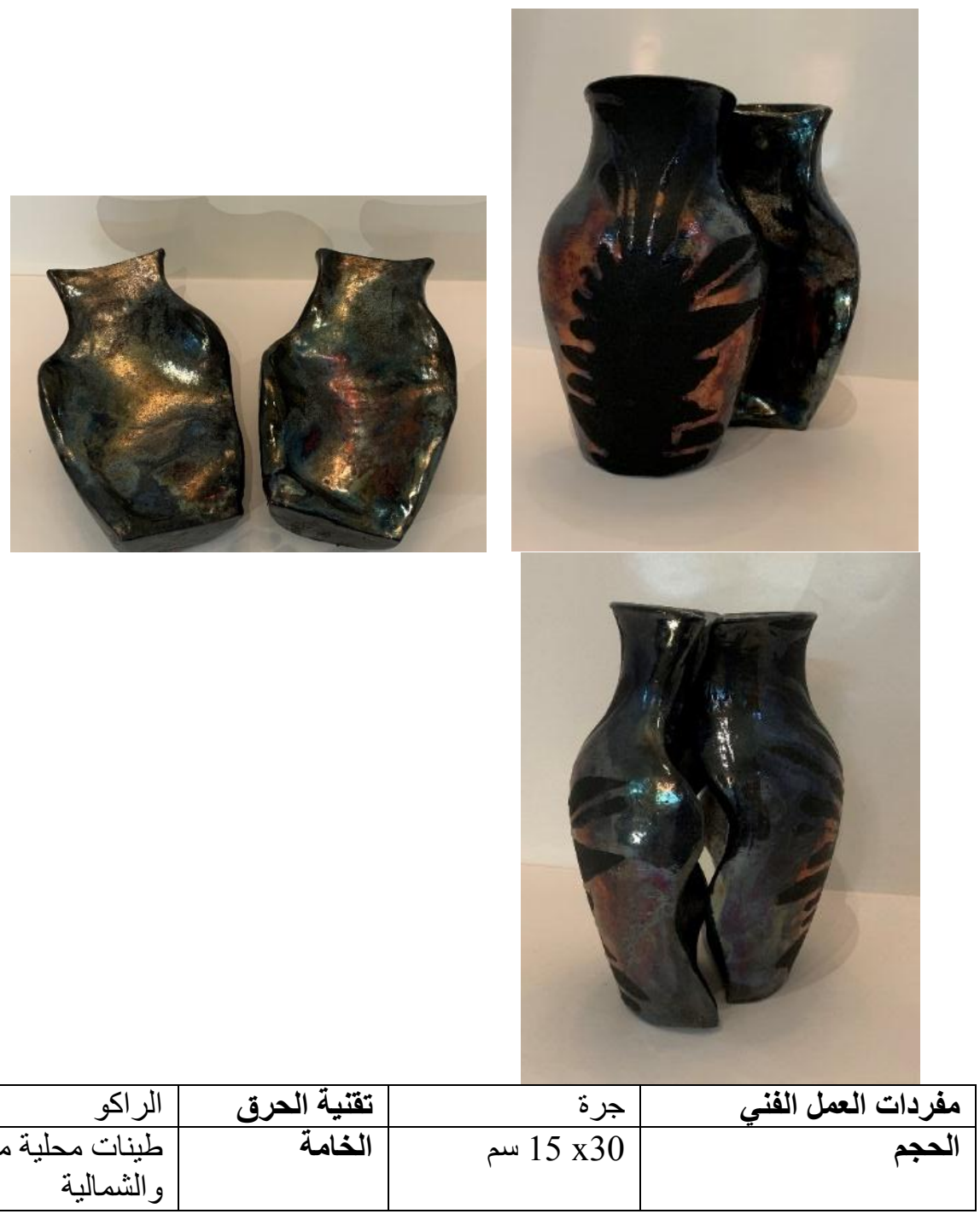

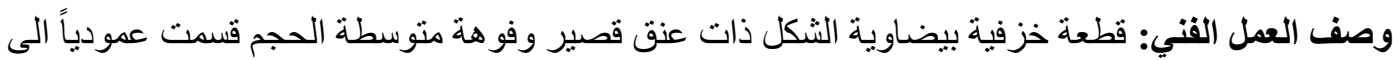

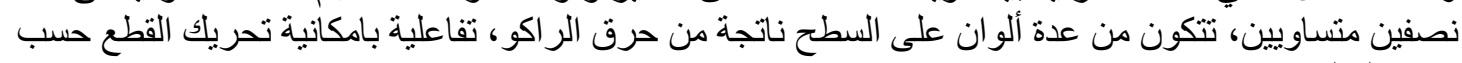
رؤية المتلقي. 


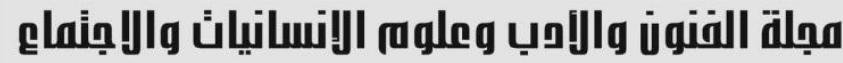

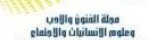

Journal of Arts, Literature, Humanities and Social Sciences www.jalhss.com

Volume (76) February 2022

فبراير 2022

العدد (76)

¿ÁLHSS

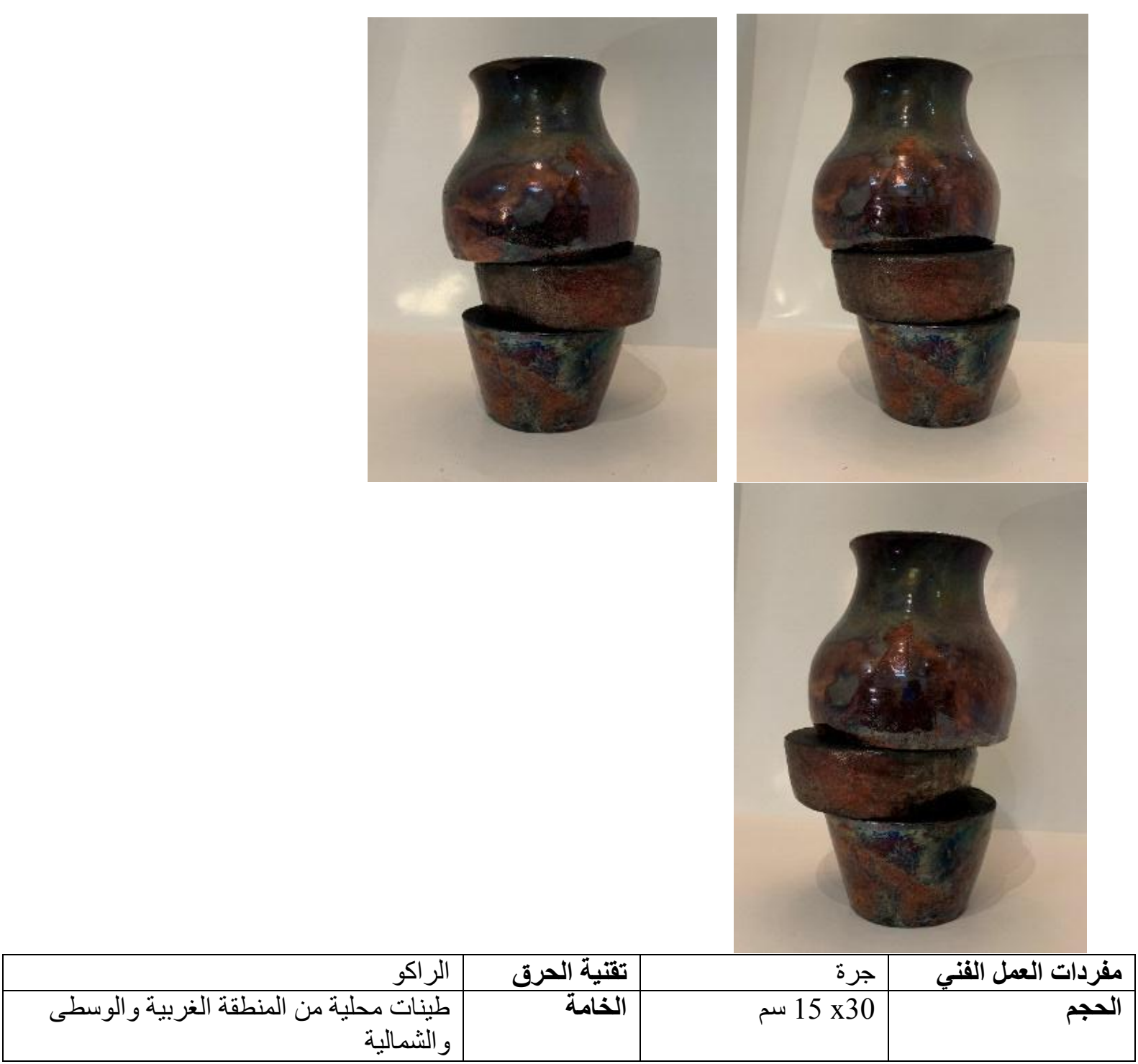

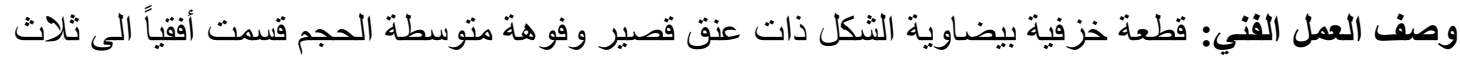
اقسام غير متساوية، تتكون من عدة ألوان على السطح ناتجة من حرق الر اكو ، تفاعلية بامكانية تحريك القطع حسب رؤية المتلقي. 


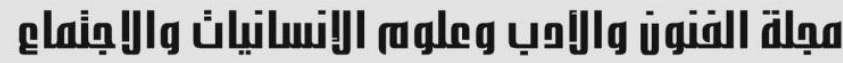

vallatianal alas

Journal of Arts, Literature, Humanities and Social Sciences www.jalhss.com

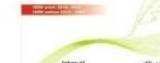

Volume (76) February 2022

فبراير 2022

العدد (76) (7) (1) (7)

¿ÁLHSS
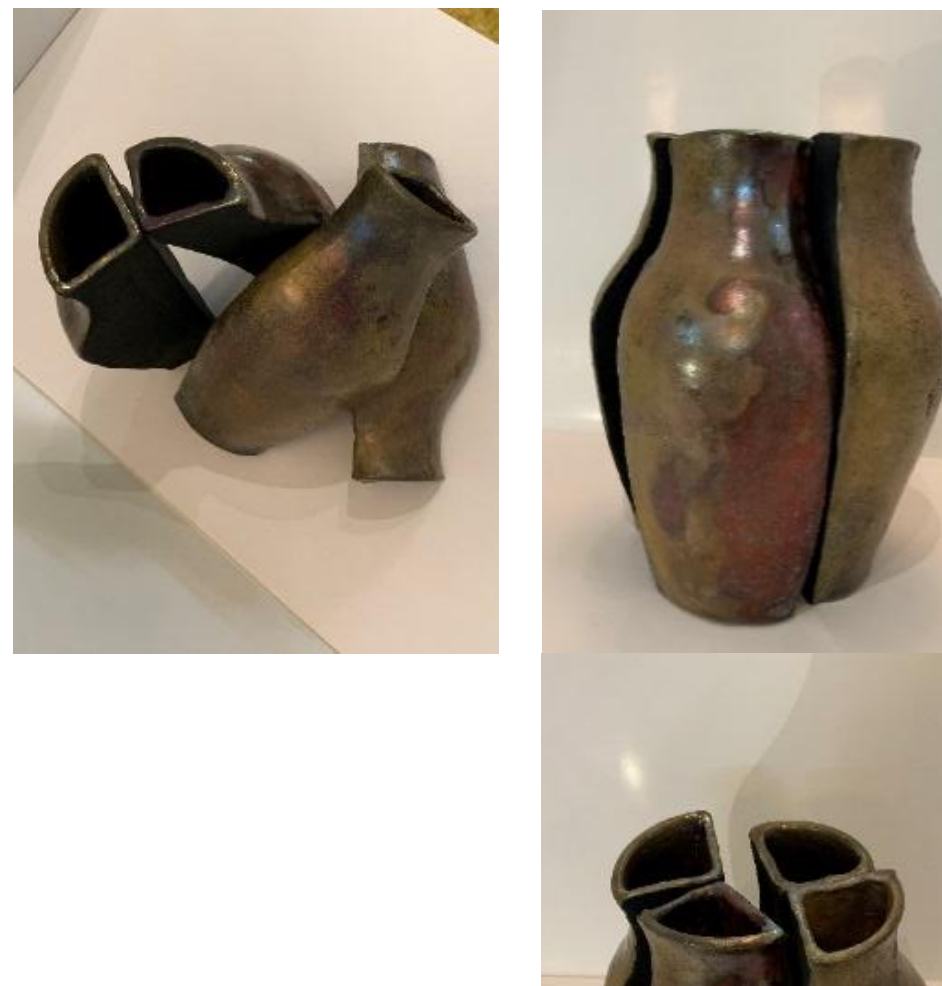

$+$

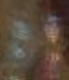

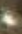

\begin{tabular}{|c|c|c|c|}
\hline الر اكو & تقنية الحرق & جرة & مفردات العمل الفني \\
\hline طو الشمالتة محلية من المنطقة الغربية و الوسطى & الخامة & x30 15 سم & الحجم \\
\hline
\end{tabular}

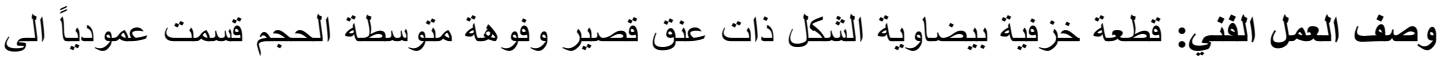

أربع اقسام منساوية، تتكون من عدة ألوان على السطح ناتجة من عملية الحرق بالر اكو ، تفاعلية بامكانية تحريك

القطع حسب رؤية المتلقي. 


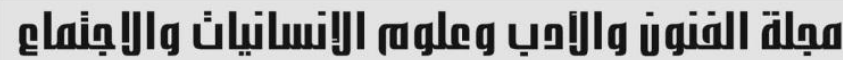

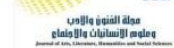

Journal of Arts, Literature, Humanities and Social Sciences www.jalhss.com

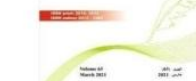

Volume (76) February 2022

العدد (76) فبراير 2022

¿ÁLHSS

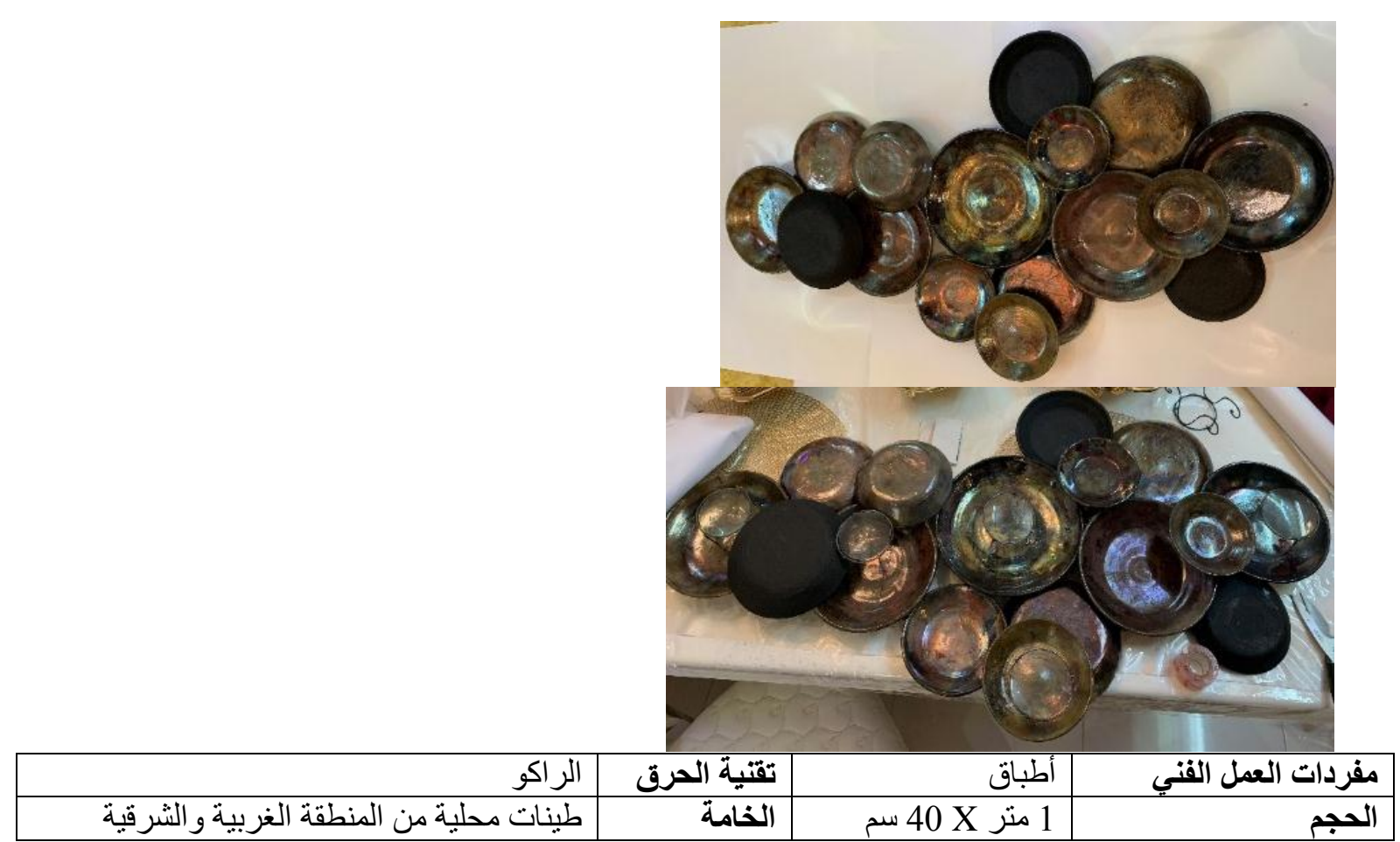

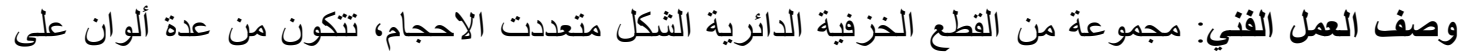

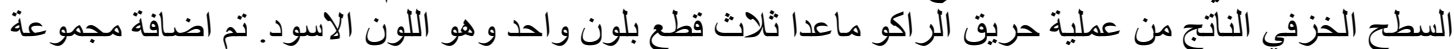

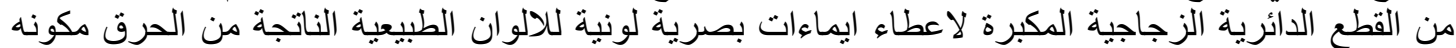

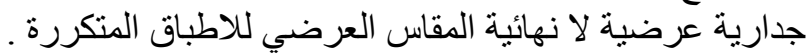

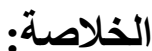

اثبتت الطينات المحلية قوة تحملها للصدمات ودرجات الحرارة المختلفة والظروف المختلفة التي قد تستخدم من

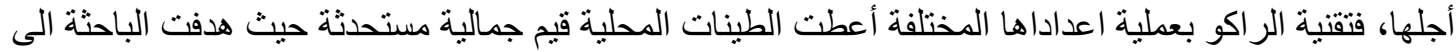

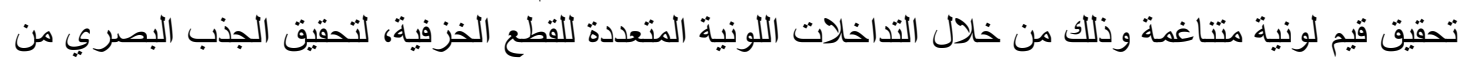

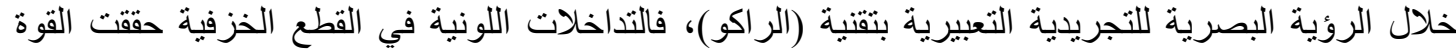

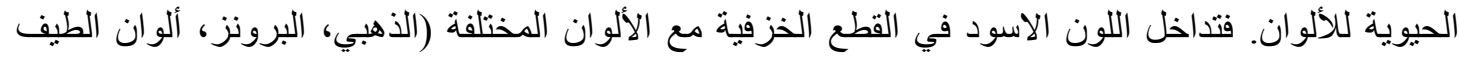

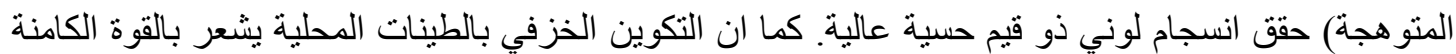

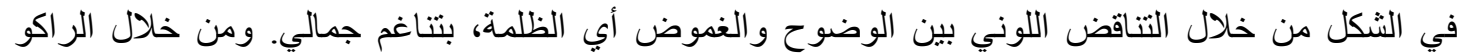

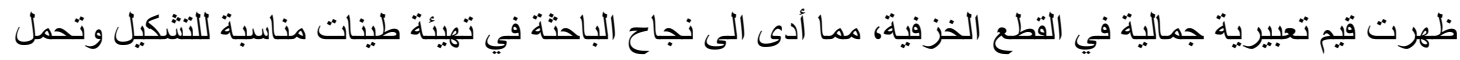
صدمات الحريق محققه التجريدات اللونية لتجاورات لونية على سطح القطع الخزفية بالطينات المحلية، وكأنها

لوحة فنية معاصرة. 


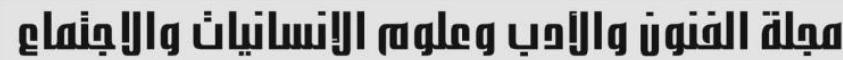

Journal of Arts, Literature, Humanities and Social Sciences www.jalhss.com

1- - ان الاو اني الخزفية التقليدية والمنتجة من الطينات المحلية مصدر لإلهام الخز افين المعاصرين. 2- ايجاد طينات محلية صالحه للتشكيل وتحمل الصدمات الصدات الحر ارية.

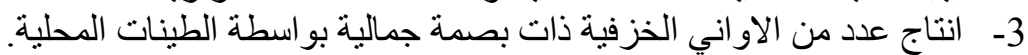

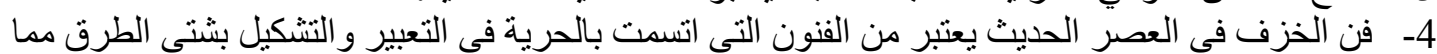

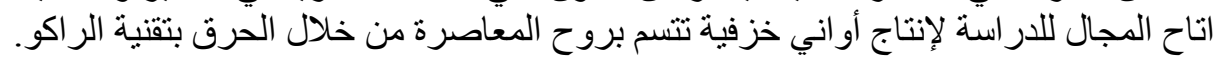
5- تقنية الحرق بالر اكو أعطت حلئ العول ابتكارية جديدة للار اسة من خلال التجريدية التعبيرية لتصميم اشكال

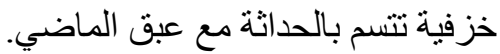
6- التعبيرية التجريدية فتحت افاق جمالية لابتكار تداخلات لونية عشو ائية بو اسطة الحرق تقنية الر اكو.

1- الاهتمام بالمخرجات الحديثة من خلاه التشكيل بو اسطة عجلة الخز اف.

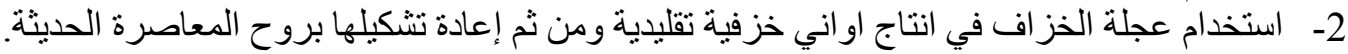

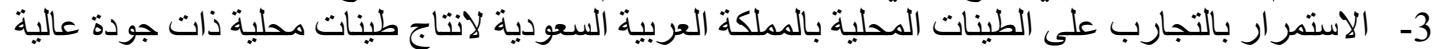
تضاهي الطينات المستوردة. 4- ابتكار حلول تشكيلية حديثة من الأواني الخزفية التقليدية واعطائها روح الحداثة من خلال اتباع فكر اتجاه التجريدية التعبيرية. 5- حث الخز افين التقليدين لابتكار اشكال خزفية وحرقها بتقنية الر اكو، وذلك للخروج من سمتها القديمة.

(1)Wandless, J. C. (2006). Alternative Kilns \& Firing Techniques. New York: A Lark Ceramics Book.

$$
\begin{aligned}
& \text { إن عطية. (2011). إتجاهات في الفن الحديث و الدعاصر . القاهرة: عالم الكتب. }
\end{aligned}
$$

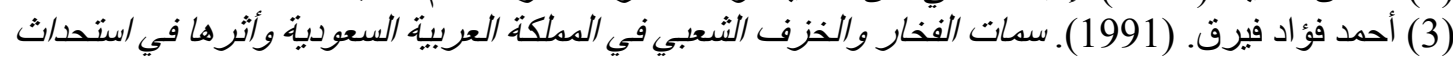

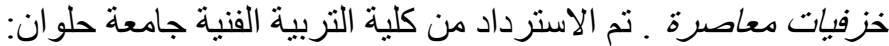

$$
\begin{aligned}
& \text { https://ia801609.us.archive.org/22/items/026VW/026VW2503.pdf } \\
& \text { (4) إبتهال حامد عثمان إدريس. (1999). الطينات الدحلية المونة واثرها في اثراء السطح الخزفي ـ تم }
\end{aligned}
$$

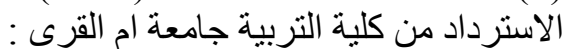
(5)Branfman, S. (2020, 08 12). Successful Tips and Techniques for Raku Firing . Retrieved from Ceramic Arts Network Daily: https://ceramicartsnetwork.org/daily/article/Successful-Tips-and-Techniques-forRaku-Firing

$$
\text { (6) محمد سعيد عبد اله. (2015). تعلم الخزف.. فن وعلم ـ القاهرة : مكتبة الأنجلو المصرية. }
$$
(7) عو اطف حمد القنيط. (2013). الفخار والفخارين في منطقة جازان. الرياض: مركز الملك فيصل للبحوث و الدر اسات الإسلامية،

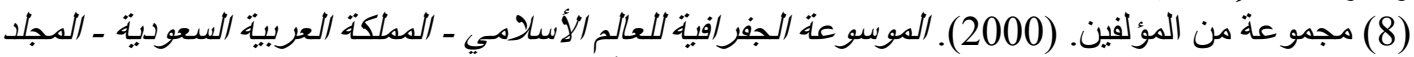

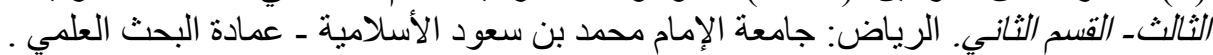

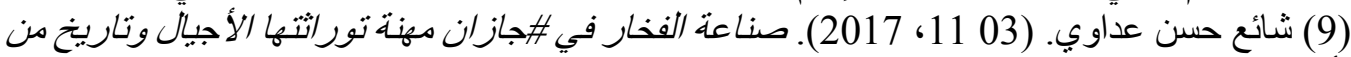

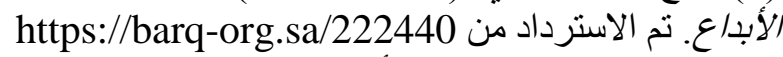
(10) سامي الكور. (2018). تأثبر كاندينسكي وموندريان على فن التصوير الأوروبي. دمشق: جامعة دمشق 


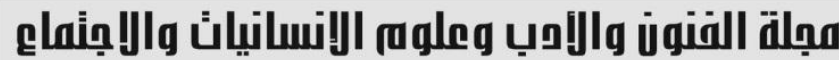 \\ Journal of Arts, Literature, Humanities and Social Sciences www.jalhss.com}

(11) رباب سلمان كاظم. (2014). ملامح ما بعد الحداثة وتجلياتها في الخزف الامريكي. بغداد: جامعة بابل كلية الفنون الجميلة. (12) حسام صباح جرد ـ منذر محمد سليمان. (2016). جماليات تقنية الر اكو في الخزف البريطاني ـ مجلة

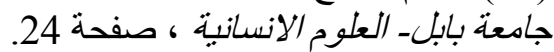
(13) خالد حسن عثمان. (2019). الخزف الان. مكة المكرمة : جامعة أم القرى. 